\title{
Impaired Insulin-stimulated Muscle Glycogen Synthase Activation In Vivo in Man Is Related to Low Fasting Glycogen Synthase Phosphatase Activity
}

\author{
D. Freymond, C. Bogardus, M. Okubo, K. Stone, and D. Mott \\ Clinical Diabetes and Nutrition Section, National Institute of Diabetes and Digestive and Kidney Diseases, \\ National Institutes of Health, Phoenix, Arizona 85016
}

\begin{abstract}
Insulin-mediated glycogen synthase activity in skeletal muscle correlates with the rate of insulin-mediated glycogen deposition and is reduced in human subjects with insulin resistance. To assess the role of glycogen synthase phosphatase as a possible mediator of reduced glycogen synthase activity, we studied 30 Southwestern American Indians with a broad range of insulin action in vivo. Percutaneous biopsies of the vastus lateralis muscle were performed before and during a 440-min euglycemic clamp at plasma insulin concentrations of $89 \pm 5$ and $1,470 \pm 49 \mu \mathrm{U} / \mathrm{ml}$ (mean \pm SEM); simultaneous glucose oxidation was determined by indirect calorimetry. After insulin stimulation, glycogen synthase activity was correlated with the total and nonoxidative glucose disposal at both low $(r=0.73$, $P<0.0001 ; r=0.68, P<0.0001)$ and high $(r=0.75, P$ $<0.0001 ; r=0.74, P<0.0001)$ plasma insulin concentrations. Fasting muscle glycogen synthase phosphatase activity was correlated with both total and nonoxidative glucose disposal rates at the low $(r=0.48, P<0.005 ; r=0.41, P<0.05)$ and high $(r=0.47, P<0.05 ; r=0.43, P<0.05)$ plasma insulin concentrations. In addition, fasting glycogen synthase phosphatase activity was correlated with glycogen synthase activity after low- $(r=0.47, P<0.05)$ and high- $(r=0.50, P<0.01)$ dose insulin stimulations. These data suggest that the decreased insulin-stimulated glucose disposal and reduced glycogen synthase activation observed in insulin resistance could be secondary to a low fasting glycogen synthase phosphatase activity.
\end{abstract}

\section{Introduction}

In vivo, insulin-stimulated skeletal muscle glycogen synthase activity is correlated with the rate of insulin-mediated glucose disposal in man (1), and these two parameters decreased in subjects with insulin resistance $(2,3)$. Glycogen synthase is the rate-limiting enzyme for glycogen synthesis (4). Its activity can be modulated by allosteric or covalent (phosphorylation or dephosphorylation) modifications of the molecule $(5,6)$. The dephosphorylated form (I form) is spontaneously active and virtually independent from the allosteric activation by glucose-6-phosphate (G6P); ${ }^{1}$ the phosphorylated form ( $\mathrm{D}$ form) is

Address reprint requests to Dr. Clifton Bogardus, Clinical Diabetes and Nutrition Section, National Institute of Diabetes and Digestive and Kidney Diseases, National Institutes of Health, 4212 North 16th Street, Room 541, Phoenix, AZ 85016.

Received for publication 28 January 1988 and in revised form 26 May 1988.

1. Abbreviations used in this paper: $\mathrm{CV}$, coefficient of variation; G6P, glucose-6-phosphate; FFM, fat free mass; LDM, total glucose disposal rate during low-dose insulin infusion.

The Journal of Clinical Investigation, Inc. Volume 82, November 1988, 1503-1509 inactive and sensitive to the action of the allosteric activator, G6P. The change from the dephosphorylated to the phosphorylated state is carried out by several protein kinases $(5,6)$; the inverse reaction is catalyzed by glycogen synthase phosphatase (protein phosphatase) (7). Insulin enhances glycogen synthase activity by a mechanism involving the activation of glycogen synthase phosphatase (8-10) and the inhibition of cAMP-dependent protein kinase $(11,12)$. The inhibition of this kinase has recently been reported to lower the phosphorylation of inhibitor-1, leading to the activation of glycogen synthase phosphatase (7).

Several studies using animal models of diabetes mellitus (13-18) have shown that diminished insulin or glucose-stimulated glycogen synthase activities are associated with decreased levels of glycogen synthase phosphatase. Such results have not been reported on human muscle. In this study, we measured fasting human muscle glycogen synthase phosphatase activity to determine its relationship with insulin-stimulated glycogen synthase activity.

\section{Methods}

30 Southwestern American Indians, 11 women and 19 men, were admitted to the clinical research ward of the Clinical Diabetes and Nutrition Section to be studied. They were selected to represent a broad range of insulin sensitivity. Their characteristics are shown in Table I. After giving written informed consent, each subject underwent a complete physical examination and an electrocardiogram. After an overnight fast, blood was drawn for complete blood count, liver function tests, blood-urea nitrogen, creatinine, electrolytes, calcium, total plasma protein, albumin, prothrombin, and partial thromboplastin times. Urinalysis was also performed. None of the subjects were taking any medication and all had a normal physical examination, electrocardiogram, and blood and urine analyses. After being on a weight-

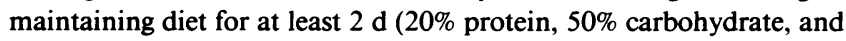
$30 \%$ fat), each subject had an oral glucose tolerance test (19), and the next morning after a 10 -h overnight fast, a hyperinsulinemic euglycemic clamp was performed. Body fat was estimated in each subject by underwater weighing with simultaneous measurement of residual lung volume (20).

Euglycemic clamp (Fig. 1). After a 10-h overnight fast, an intravenous catheter was placed in an antecubital vein for infusion of insulin, glucose, and $3-\left[{ }^{3} \mathrm{H}\right]$ glucose. Another catheter was inserted retrograde in a dorsal hand vein of the contralateral hand for blood withdrawal. The hand was kept in a warming box $\left(70^{\circ} \mathrm{C}\right)$ during the entire clamp procedure. The clamp was initiated by a primed continuous low-dose insulin infusion ( $40 \mathrm{mU} / \mathrm{m}^{2}$ per $\mathrm{min}$ ) for $360 \mathrm{~min}$. The fasting plasma insulin concentration, determined on plasma samples drawn at time -27 and $-16 \mathrm{~min}$ before the start of the insulin infusion was (mean $\pm \mathrm{SEM}$ ) $20 \pm 2 \mu \mathrm{U} / \mathrm{ml}$ (mean coefficient of variation (CV) $=8.2 \pm 1.3 \%$ ), and was $89 \pm 5 \mu \mathrm{U} / \mathrm{ml}$ (mean $\mathrm{CV}=4.8 \pm 0.6 \%$ ) in plasma samples drawn at times 315 and $330 \mathrm{~min}$ of the low-dose insulin infusion. A primed $(30 \mu \mathrm{Ci})$-continuous $(0.30 \mu \mathrm{Ci} / \mathrm{min})$ infusion of 3-[ $\left.{ }^{3} \mathrm{H}\right]$ glucose was begun at $180 \mathrm{~min}$ of the low-dose insulin infusion and continued until $340 \mathrm{~min}$. Another primed-continuous insulin infusion $\left(400 \mathrm{mU} / \mathrm{m}^{2}\right.$ per $\mathrm{min}$ ) was started after $360 \mathrm{~min}$ and continued for $80 \mathrm{~min}$. This resulted in a mean plasma insulin concentration of 


\begin{tabular}{|c|c|c|c|c|c|c|c|c|}
\hline \multirow[b]{2}{*}{ Subjects } & \multirow[b]{2}{*}{ Sex } & \multirow[b]{2}{*}{ Age } & \multirow[b]{2}{*}{ Body weight } & \multirow[b]{2}{*}{ Body fat } & \multicolumn{2}{|c|}{ Fasting plasma } & \multicolumn{2}{|c|}{$\begin{array}{c}\text { 2-h oral glucose tolerance } \\
\text { test plasma }\end{array}$} \\
\hline & & & & & Glucose & Insulin & Glucose & Insulin \\
\hline & & $y r$ & $k g$ & $\%$ & $m g / d l$ & $\mu U / m l$ & $m g / d l$ & $\mu U / m l$ \\
\hline 1 & $\mathbf{M}$ & 23 & 93.1 & 23 & 85 & 4 & 112 & 15 \\
\hline 2 & $\mathbf{M}$ & 21 & 55.2 & 10 & 87 & 9 & 106 & 21 \\
\hline 3 & $\mathbf{M}$ & 23 & 58.6 & 16 & 88 & 5 & 129 & 58 \\
\hline 4 & $\mathbf{M}$ & 30 & 77.0 & 27 & 89 & 7 & 100 & 68 \\
\hline 5 & $\mathbf{M}$ & 26 & 72.8 & 20 & 89 & 14 & 115 & 91 \\
\hline 6 & $\mathbf{M}$ & 21 & 120.6 & 30 & 95 & 38 & 101 & 75 \\
\hline 7 & $\mathbf{M}$ & 26 & 77.4 & 19 & 96 & 11 & 109 & 32 \\
\hline 8 & $\mathbf{M}$ & 20 & 96.3 & 27 & 96 & 7 & 90 & 15 \\
\hline 9 & $\mathbf{M}$ & 30 & 97.9 & 28 & 96 & 8 & 92 & 26 \\
\hline 10 & F & 18 & 90.4 & 34 & 98 & 19 & 101 & 60 \\
\hline 11 & F & 38 & 121.5 & 45 & 100 & 35 & 153 & 245 \\
\hline 12 & $\mathbf{M}$ & 34 & 73.6 & 13 & 102 & 6 & 71 & 76 \\
\hline 13 & $\mathbf{M}$ & 42 & 148.1 & 42 & 103 & 33 & 128 & 236 \\
\hline 14 & $\mathbf{M}$ & 19 & 57.2 & 13 & 103 & 4 & 96 & 13 \\
\hline 15 & $\mathbf{M}$ & 41 & 127.5 & 43 & 105 & 27 & 73 & 68 \\
\hline 16 & $\mathbf{M}$ & 39 & 115.3 & 37 & 106 & 13 & 150 & 89 \\
\hline 17 & $\mathbf{F}$ & 36 & 107.4 & 40 & 109 & 33 & 195 & 239 \\
\hline 18 & $F$ & 21 & 124.3 & 41 & 117 & 34 & 127 & 145 \\
\hline 19 & $F$ & 31 & 98.9 & 42 & 124 & 56 & 184 & 399 \\
\hline 20 & $\mathbf{M}$ & 26 & 124.6 & 36 & 132 & 46 & 265 & 137 \\
\hline 21 & $\mathbf{M}$ & 24 & 120.1 & 30 & 134 & 20 & 167 & 41 \\
\hline 22 & $\mathbf{M}$ & 30 & 93.5 & 29 & 190 & 6 & 285 & 8 \\
\hline 23 & $\mathbf{M}$ & 28 & 100.4 & 31 & 200 & 28 & 315 & 68 \\
\hline 24 & $F$ & 21 & 104.1 & 32 & 205 & 23 & 651 & 33 \\
\hline 25 & $\mathbf{F}$ & 25 & 129.7 & 45 & 206 & 19 & 308 & 31 \\
\hline 26 & $\mathbf{M}$ & 35 & 86.1 & 25 & 218 & 10 & 328 & 10 \\
\hline 27 & $F$ & 31 & 154.6 & 46 & 255 & 14 & 341 & 14 \\
\hline 28 & $\mathbf{F}$ & 38 & 120.2 & 42 & 261 & 6 & 344 & 8 \\
\hline 29 & $\mathrm{~F}$ & 31 & 92.1 & 36 & 262 & 29 & 371 & 35 \\
\hline 30 & $F$ & 34 & 116.1 & 43 & 296 & 20 & 430 & 32 \\
\hline
\end{tabular}

$1,470 \pm 49 \mu \mathrm{U} / \mathrm{ml}($ mean $\mathrm{CV}=6.0 \pm 0.7 \%)$ on plasma samples drawn at 410 and $425 \mathrm{~min}$.

The lower plasma insulin concentration reached during the lowdose insulin infusion was considered to be within the physiologic range for this study population, since mean peak plasma insulin concentration during the oral glucose tolerance test was $137 \pm 21 \mu \mathrm{U} / \mathrm{ml}$. The higher plasma insulin concentration reached during the high-dose insulin infusion was assumed to be a maximally stimulating insulin concentration (21).

After the start of the initial insulin infusion, a variable infusion of $20 \%$ glucose was given as necessary to maintain the plasma glucose concentration between 100 and $105 \mathrm{mg} / \mathrm{dl}$ for all subjects. In the hy-
INSULIN INFUSION $\left(\mathrm{mU} / \mathrm{m}^{2} \mathrm{~min}\right)$

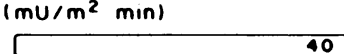

$\left[3 \cdot{ }^{3}\right.$ H $]$ GLUCOSE INFUSION
400
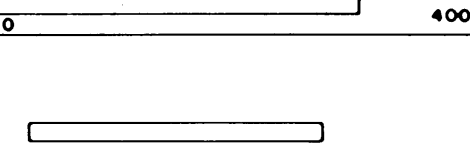

MEASUREMENT OF GLUCOSE INFUSION RATE ANO GLUCOSE OXIDATION
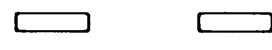

MUSCLE BIOPSY $\square$

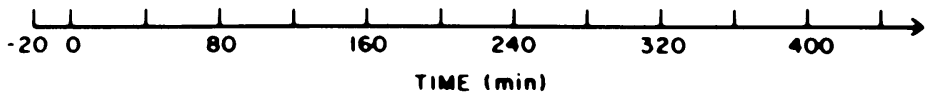

Figure 1. Synoptic diagram of the hyperinsulinemic, euglycemic clamp. 
perglycemic subjects, the glucose infusion was not begun until the plasma glucose concentration had declined to $100 \mathrm{mg} / \mathrm{dl}$. Blood for plasma glucose determination was drawn every $10 \mathrm{~min}$ until the start of the glucose infusion in the hyperglycemic patients, and then every 5 min throughout the rest of the test, as for the remaining patients. The mean plasma glucose concentration for all subjects was $103 \pm 0.5 \mathrm{mg} / \mathrm{dl}$ (mean CV $=2.5 \pm 0.3 \%$ ) during the $300-340$-min period of the lowdose insulin infusion and was $103 \pm 0.5 \mathrm{mg} / \mathrm{dl}$ (mean $\mathrm{CV}=3.9 \pm 0.3 \%$ ) between $\mathbf{4 0 0}$ and $\mathbf{4 4 0} \mathrm{min}$ of the high-dose insulin infusion. Blood for plasma $3-\left[{ }^{3} \mathrm{H}\right]$ glucose specific activity determination was drawn every $10 \mathrm{~min}$ from 300 to $340 \mathrm{~min}$ to calculate the glucose appearance rate (see below).

Indirect calorimetry. Starting at $280 \mathrm{~min}$ of the low-dose insulin infusion for the rest of the clamp, indirect calorimetric measurements were performed as follows: a clear plastic, ventilated hood was placed over the subject's head. Room air was drawn through the hood and its flow rate measured by a pneumotachograph (Gould Inc., Recording Systems Div., Cleveland, $\mathrm{OH}$ ). A constant amount of expired air mixed with room air within the hood was aspirated and analyzed for its carbon dioxide and oxygen fractions. The oxygen analyzer was a Zirconium cell analyzer and the carbon dioxide analyzer was an infrared analyzer (both by Applied Electrochemistry Inc., Sunnyvale, CA). The gas analyzers and the flowmeter were connected to a desktop computer (Hewlett-Packard Co., Palo Alto, CA). The computer recorded continuous, integrated, 5-min calorimetric measurements used for calculations between 300 and 340 and 400 and $440 \mathrm{~min}$, according to the start of the insulin infusion. The protein oxidation rate during the test was estimated from urea nitrogen production rate measured in the urine collected during the clamp. The nonprotein respiratory quotient was then calculated and the substrate oxidation rates were determined from the equations of Lusk (22).

Muscle biopsy, glycogen synthase, and glycogen synthase phosphatase determination. During the $15 \mathrm{~min}$ before the start of the insulin infusion, the first of three percutaneous muscle biopsies of the vastus lateralis muscle was performed with local anesthesia. The samples were collected in two or three passes with a Bergström (Depuy, Phoenix, AZ) muscle biopsy needle, to which vacuum was applied by a $60-\mathrm{ml}$ syringe via a $100-\mathrm{cm}$ plastic connecting tube. The specimens were frozen in liquid nitrogen within $15 \mathrm{~s}$.

The second muscle biopsy was performed on the contralateral thigh between 340 and $360 \mathrm{~min}$, while insulin continued to be infused at the same speed and the glycemia was controlled; the third muscle biopsy was performed between 440 and $460 \mathrm{~min}$ at a site that was 10 $\mathrm{cm}$ more proximal than the first muscle biopsy. 10 times more insulin continued to be infused than was infused during the second muscle biopsy.

The samples were stored at $-70^{\circ} \mathrm{C}$ and assayed later for glycogen synthase activity (2). Physiologically active glycogen synthase was assayed at a low G6P concentration $(0.17 \mathrm{mM})$ and is expressed as units per gram wet weight. Total glycogen synthase activity (U/g wet wt) was assayed at a high G6P concentration $(10.8 \mathrm{mM})$. Glycogen synthase phosphatase activity was assayed as follows: muscle pieces were homogenized 1:32 (wt/vol) in $50 \mathrm{mM}$ Tris, $10 \mathrm{mM}$ EDTA, and $50 \mathrm{mM}$ 2-mercaptoethanol, pH 7.8, for $3 \mathrm{~s}$ at $4^{\circ} \mathrm{C}$ on the VirTis 45 homogenizer (VirTis Co., Gardiner, NY). The homogenate was centrifuged at $10,000 \mathrm{~g}$ for $20 \mathrm{~min}$ at $4^{\circ} \mathrm{C}$ and the supernatant was used for the glycogen synthase phosphatase assay. The assay was started by adding $100 \mu \mathrm{l}$ of supernatant to a mixture containing $\sim 25 \mathrm{mU}$ rabbit glycogen synthase D (EC 2.4.1.11, Sigma Chemical Co., St. Louis, MO) in a final volume of $175 \mu \mathrm{l}$, as previously reported (23). Rabbit glycogen synthase $\mathrm{D}$ was preincubated at $30^{\circ} \mathrm{C}$ for $20 \mathrm{~min}$ before use. The phosphatase reaction at $30^{\circ} \mathrm{C}$ was stopped by diluting $25 \mu \mathrm{l}$ of the incubation mixture with $40 \mathrm{vol}$ of $130 \mathrm{mM}$ potassium fluoride, $50 \mathrm{mM}$ Tris, and $20 \mathrm{mM}$ EDTA, pH 7.8 , at $4^{\circ} \mathrm{C}$. Glycogen synthase activity was then assayed as previously described (2). Glycogen synthase phosphatase activity is expressed as the change in the active form of synthase activity per 20 min corrected per gram tissue wet weight. One unit equals a change of synthase activity equal to the incorporation of 1 $\mu \mathrm{mol}$ UDP-glucose into glycogen per minute. The phosphatase assay was linear with time and enzyme concentration under conditions where fractional glycogen synthase activities (physiologic/total) did not exceed 0.7 . Glycogen and glycogen phosphorylase were assayed as previously described (2).

Calculations and analyses. The appearance rate of glucose in the plasma was calculated from the blood $3-\left[{ }^{3} \mathrm{H}\right]$ glucose specific activities using Steele's nonsteady state equations (24). The total glucose disposal rate during the low-dose insulin infusion (LDM) is equal to the glucose appearance rate assessed at the same time. When the isotopically determined appearance rate was equal to or smaller than the exogenous glucose infusion rate, the endogenous glucose production rate was assumed to be fully suppressed and then LDM equaled exogenous glucose infusion rate. The glucose infusion rate was calculated for each 20 -min period between 300 and 340 and 400 and $440 \mathrm{~min}$, i.e., during the last $40 \mathrm{~min}$ of the low- and high-dose insulin infusions, respectively; they were averaged to obtain the mean total glucose disposal rate during the two insulin infusions. The insulin-stimulated carbohydrate oxidation rates were calculated from the indirect calorimetry data by also using the mean values obtained during the same corresponding last $\mathbf{4 0} \mathrm{min}$ of both infusions. The carbohydrate nonoxidative disposal rate (storage rate), expressed in $\mathrm{mg} / \mathrm{kg}$ fat free mass (FFM) per min was considered as the difference between the total glucose disposal rate and the carbohydrate oxidation rate. Plasma insulin concentrations were determined by RIA and tritiated glucose specific activity in blood samples was determined after precipitating protein with perchloric acid (25).

Statistics. All data are expressed as mean \pm SEM. Intersituational comparisons were performed using the paired $t$ test. Sample correlations are Pearson product-moment correlations.

\section{Results}

Glycogen synthase (Table II). Muscle glycogen synthase activities obtained before insulin infusion ranged from 0.12 to 0.64 $\mathrm{U} / \mathrm{g}$ wet wt. The insulin-stimulated glycogen synthase activities were positively correlated with the respective mean total and nonoxidative insulin-stimulated glucose disposal rates at the end of the low $(r=0.73, P<0.0001 ; r=0.68, P<0.0001$, respectively) and the high $(r=0.75, P<0.0001 ; r=0.74$, $P<0.0001$ ) insulin infusion rates (Fig. 2, $A$ and $B$ ).

Total glycogen synthase activity was unchanged from the fasting $(0.64 \pm 0.03 \mathrm{U} / \mathrm{g}$ wet $\mathrm{wt})$ to the low-dose insulin-stimulated state $(0.69 \pm 0.03 \mathrm{U} / \mathrm{g}$ wet $\mathrm{wt})$, but increased between the fasting and the high-dose insulin-stimulated conditions $(0.72 \pm 0.03 \mathrm{U} / \mathrm{g}$ wet wt, $P<0.01)$. Fasting glycogen synthase and total glycogen synthase activities were not correlated with low or high-dose insulin-stimulated total and nonoxidative glucose disposal rates.

Glycogen synthase phosphatase. Fasting phosphatase activity ranged from 0.25 to $1.53 \mathrm{U} / \mathrm{g}$ wet wt and was positively correlated with total and nonoxidative insulin-mediated glucose disposal rates at both low $(r=0.48, P<0.05 ; r=0.41$, $P<0.05$, respectively) and high $(r=0.47, P<0.05 ; r=0.43$, $P<0.05$, respectively) rates of insulin infusion (Fig. 3, $A$ and $B$ ).

Fasting phosphatase activities were also positively correlated with the glycogen synthase activities measured at the end of the low $(r=0.47, P<0.05)$ and high $(r=0.50, P<0.01)$ rates of insulin infusion (Fig. $4, A$ and $B$ ). Fasting muscle glycogen content and phosphorylase a were not correlated with glycogen synthase phosphatase (data not shown).

The effect of insulin stimulation on glycogen synthase phosphatase activity during the euglycemic clamp was measured in 23 subjects. In this subgroup the fasting phosphatase 
Table II. Muscle Glycogen Synthase and Glycogen Synthase Phosphatase Activities before, during, and at the End of the Clamp Procedure with Corresponding Glucose Disposal and Oxidation Rates

\begin{tabular}{|c|c|c|c|c|c|c|c|c|}
\hline \multirow[b]{2}{*}{ Subject } & \multicolumn{3}{|c|}{ Glycogen synthase activity } & \multicolumn{2}{|c|}{$\begin{array}{l}\text { Glucose disposal rate at } \\
\text { low-dose insulin }\end{array}$} & \multicolumn{2}{|c|}{$\begin{array}{l}\text { Glucose disposal rate at } \\
\text { high-dose insulin }\end{array}$} & \multirow{2}{*}{$\begin{array}{c}\text { Glycogen } \\
\text { synthase } \\
\text { phosphatase } \\
\text { F }\end{array}$} \\
\hline & $\mathbf{F}$ & L & $\mathbf{H}$ & Total & Oxidative & Total & Oxidative & \\
\hline & \multicolumn{3}{|c|}{$U / g$ wet $w t$} & \multicolumn{4}{|c|}{$m g / k g$ FFM per min } & $U / g$ wet $w t$ \\
\hline 1 & 0.26 & 0.45 & 0.55 & 9.5 & 3.1 & 12.4 & 3.7 & 1.05 \\
\hline 2 & 0.43 & 0.67 & 0.68 & 8.9 & 3.4 & 12.4 & 4.2 & 1.27 \\
\hline 3 & 0.36 & 0.83 & 0.52 & 9.5 & 3.3 & 11.8 & 4.3 & 1.12 \\
\hline 4 & 0.36 & 0.58 & 0.79 & 10.9 & 4.0 & 16.7 & 5.2 & 1.28 \\
\hline 5 & 0.28 & 0.53 & 0.58 & 7.3 & 2.9 & 12.0 & 3.9 & 1.04 \\
\hline 6 & 0.30 & 0.41 & 0.53 & 4.3 & 2.0 & 11.0 & 3.2 & 1.04 \\
\hline 7 & 0.26 & 0.54 & 0.61 & 10.6 & 3.2 & 15.6 & 4.3 & 1.41 \\
\hline 8 & 0.49 & 0.64 & 0.63 & 11.4 & 2.6 & 16.0 & 3.8 & 0.69 \\
\hline 9 & 0.33 & 0.40 & 0.60 & 10.5 & 3.0 & 14.1 & 4.7 & - \\
\hline 10 & 0.24 & 0.51 & 0.67 & 6.3 & 3.4 & 16.0 & 5.6 & 1.53 \\
\hline 11 & 0.34 & 0.48 & 0.57 & 5.4 & 2.9 & 13.4 & 4.4 & 0.94 \\
\hline 12 & 0.29 & 0.38 & 0.55 & 8.6 & 2.5 & 13.1 & 3.2 & 1.07 \\
\hline 13 & 0.48 & 0.53 & 0.57 & 3.5 & 1.6 & 9.5 & 3.2 & 1.10 \\
\hline 14 & 0.23 & 0.67 & 0.61 & 12.3 & 5.3 & 16.1 & 6.9 & - \\
\hline 15 & 0.31 & 0.36 & 0.43 & 4.0 & 2.4 & 14.3 & 4.8 & 0.83 \\
\hline 16 & 0.38 & 0.43 & 0.77 & 4.2 & 2.3 & 10.8 & 3.5 & 0.72 \\
\hline 17 & 0.28 & 0.36 & 0.46 & 5.3 & 3.3 & 12.5 & 4.3 & 0.48 \\
\hline 18 & 0.19 & 0.37 & 0.76 & 3.2 & 1.3 & 11.1 & 2.4 & 1.15 \\
\hline 19 & 0.28 & 0.29 & 0.32 & 3.6 & 3.3 & 11.1 & 4.0 & 0.96 \\
\hline 20 & 0.40 & 0.27 & 0.40 & 2.7 & 1.8 & 6.9 & 3.6 & 0.25 \\
\hline 21 & 0.64 & 0.58 & 0.57 & 3.9 & 2.0 & 13.0 & 3.2 & 1.01 \\
\hline 22 & 0.38 & 0.24 & 0.60 & 5.8 & 3.6 & 11.4 & 4.2 & 1.16 \\
\hline 23 & 0.29 & 0.13 & 0.16 & 2.8 & 1.1 & 2.7 & 2.6 & 0.70 \\
\hline 24 & 0.25 & 0.13 & 0.18 & 2.8 & 1.3 & 4.7 & 2.4 & 0.99 \\
\hline 25 & 0.12 & 0.11 & 0.11 & 2.4 & 1.9 & 4.4 & 3.1 & 0.82 \\
\hline 26 & 0.33 & 0.20 & 0.30 & 3.5 & 1.9 & 8.9 & 3.2 & - \\
\hline 27 & 0.37 & 0.16 & 0.31 & 2.1 & 1.1 & 7.2 & 2.6 & 0.82 \\
\hline 28 & 0.29 & 0.16 & 0.16 & 2.8 & 0.6 & 10.9 & 2.6 & 0.64 \\
\hline 29 & 0.32 & 0.32 & 0.45 & 3.9 & 1.5 & 10.5 & 2.5 & 0.76 \\
\hline 30 & 0.28 & 0.35 & 0.28 & 2.6 & 1.2 & 8.9 & 2.4 & 0.84 \\
\hline
\end{tabular}

$F$, fasting condition; $L$, at the end of the low-dose insulin infusion; $H$, at the end of the high-dose insulin infusion.

activity (mean $=0.96 \pm 0.05 \mathrm{U} / \mathrm{g}$ wet $\mathrm{wt}$ ) remained correlated with insulin-stimulated glycogen synthase activity $(r=0.46$, $P<0.005 ; r=0.47, P<0.05)$ and glucose disposal rates $(r=0.43, P<0.05 ; r=0.47, P<0.05)$ measured at the end of

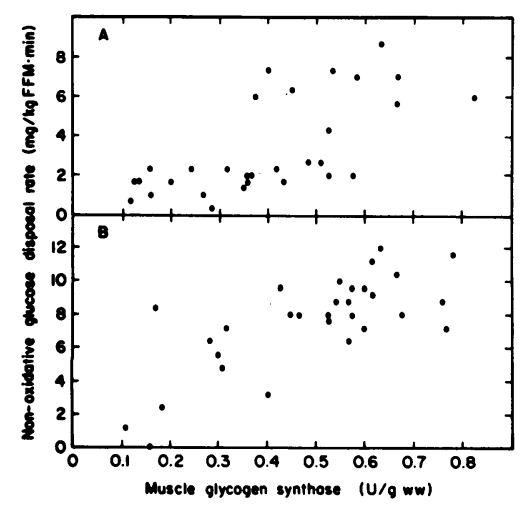

Figure 2. Relationships between the nonoxidative glucose disposal rate at a plasma glucose concentration of $103 \pm 0.5 \mathrm{mg} / \mathrm{dl}$ and glycogen synthase activity at a plasma insulin concentration of $(A) 89 \pm 5$ $(r=0.68, P<0.0001)$ and $(B) 1,470 \pm 49$ $\mu \mathrm{U} / \mathrm{ml}(r=0.74, P$ $<0.0001)$. the low and high rates of insulin infusion, respectively. Phosphatase activity measured at the end of the low rate of insulin infusion (mean $=0.93 \pm 0.04 \mathrm{U} / \mathrm{g}$ wet $\mathrm{wt}$ ) was not increased but did correlate with the low dose insulin-stimulated glycogen synthase activity ( $r=0.43, P<0.05$, data not shown) but not with the low-dose, insulin-stimulated glucose disposal rate. Phosphatase activity measured at the end of the high rate of insulin infusion (mean $=0.91 \pm 0.05 \mathrm{U} / \mathrm{g}$ wet $w \mathrm{t}$ ) was not significantly different from fasting activity and was not correlated with either synthase activity or insulin-stimulated glucose disposal rates.

\section{Discussion}

We previously reported (2) that insulin-stimulated glucose disposal rates (and nonoxidative glucose disposal rates) were correlated with insulin-stimulated skeletal muscle glycogen synthase activity in vivo in man; glycogen synthase activities also correlated with insulin-stimulated muscle glycogen accretion. 


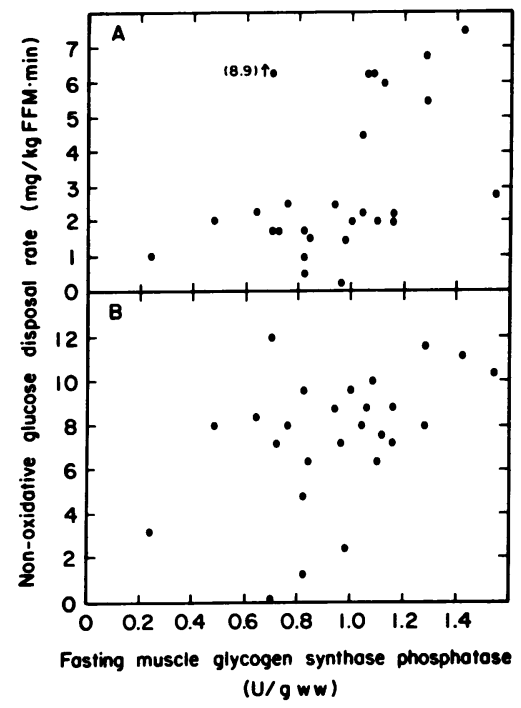

Figure 3. Relationships between fasting glycogen synthase phosphatase activity and nonoxidative glucose disposal rate after $(A)$ low- and $(B)$ high-dose insulin infusions $(r=0.41, P$ $<0.05 ; r=0.43, P$ $<0.05$, respectively).

In this study, we determined the relationship between insulinstimulated muscle glycogen synthase and glycogen synthase phosphatase activities. Firstly, our results confirm the relationship between insulin-stimulated total and nonoxidative glucose disposal and muscle glycogen synthase activity. Secondly, they show that in human muscle, fasting glycogen synthase phosphatase activity is linearly correlated with physiologically and maximally insulin-stimulated total and nonoxidative glucose disposal and glycogen synthase activity. The subjects whose glycogen synthase is least activated by insulin are those with the lowest fasting glycogen synthase phosphatase levels.

A recent in vivo study in Caucasians with normal glucose tolerance (1) confirmed our previously reported data (2) showing that the rate of insulin-stimulated nonoxidative glucose disposal correlated with insulin-stimulated muscle glycogen synthase activity. Muscle glycogen synthase is also less activated by insulin in type I diabetic human subjects, in whom total glycogen synthase activity is not reduced (26). To our knowledge, however, human glycogen synthase phospha-

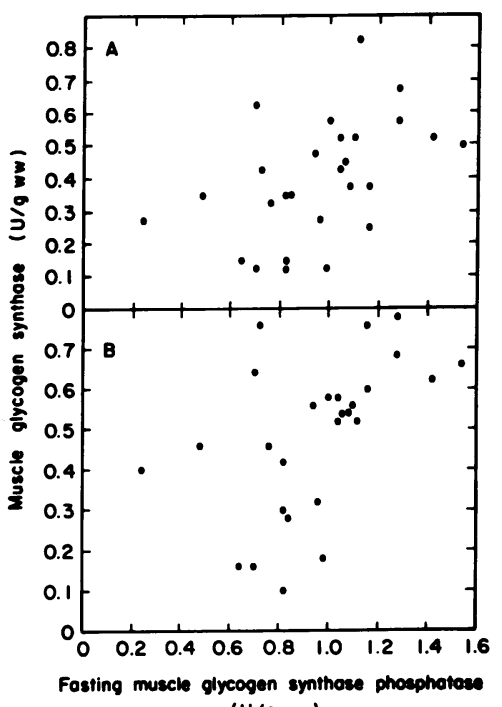

(U/g ww)
Figure 4. Relationships between the fasting glycogen synthase phosphatase activities and the glycogen synthase activities after $(A)$ low$(r=0.47, P<0.05)$ and (B) high- $(r=0.50, P$ $<0.01)$ dose insulin infusions. tase has only been measured in PMN $(27,28)$. Glycogen synthase and glycogen synthase phosphatase have been studied in animal experiments in several different tissues. In studies on rat hepatocytes (13-16), perfused rat hearts (17), and rabbit skeletal muscle (18), insulin deprivation was associated with a decrease in glycogen synthase phosphatase levels in proportion to the severity of insulin deprivation $(15,16)$. In diabetic animals, low glycogen synthase phosphatase activities have been associated with low fasting glycogen synthase activities $(14,15$, 17), although in one study on diabetic rat muscle (29), only glycogen synthase activity is decreased, but not glycogen synthase phosphatase. In this study, human muscle fasting glycogen synthase activity is not correlated with insulin-stimulated glucose disposal, suggesting that the insulin-resistant subjects do not have an abnormality in their fasting glycogen synthase activities.

The total amount of glycogen synthase is not decreased in diabetic animals $(14,17,29)$; it takes $72 \mathrm{~h}$ of fasting to show a decrease in rat heart (30). In our results, the fasting total glycogen synthase activity is not correlated with insulin-stimulated glucose disposal and thus, like fasting glycogen synthase activity, does not seem to be related to the degree of insulin resistance. Total glycogen synthase shows a significant increase after $\mathbf{4 4 0} \mathrm{min}$ of insulin infusion, which may be due to de novo synthesis of the enzyme.

Similar to our results, decreased glycogen synthase phosphatase has been associated with decreased acute in vitro activation of glycogen synthase by glucose $(13,14,16)$ or insulin $(14,17)$ in animal experiments. Decreased glycogen synthase phosphatase and reduced insulin-stimulated glycogen synthase activities have also been observed after fasting in rat heart (30, 31).

In diabetic animals, acute in vitro activation of glycogen synthase can be recovered, at least partly, by previous in vivo $(15-17,29)$ or in vitro $(13,14)$ insulin treatment; this is associated with restored normal levels of glycogen synthase phosphatase, reached in $1-68 \mathrm{~h}(16,17)$. Inhibitors of protein synthesis, administered with insulin in vivo (17) or in vitro (13), prevent glycogen synthase phosphatase of diabetic tissue from reaching control levels, and they prevent the acute reactivation of glycogen synthase by insulin, whereas total glycogen synthase is not influenced.

Based on animal studies, lower fasting glycogen synthase phosphatase levels in man may be the result of $(a)$ abnormal regulator activity (inhibition and/or activation), (b) an abnormal substrate, or $(c)$ a decreased amount of the enzyme.

Glycogen synthase phosphatase may be inhibited (27, 32, 33) by phosphorylase a, the active form of phosphorylase; this regulation mechanism of glycogen synthase phosphatase is controversial $(16,34)$. In our study, there is no correlation between fasting phosphorylase a and glycogen synthase phosphatase (data not shown). Tissue glycogen content, referred to as an inhibitor of glycogen synthase phosphatase (35), was not correlated in our study with glycogen synthase phosphatase activity in the fasting condition. The quantitatively and chronologically adequate rise of intracellular peptidic mediators released by insulin (8) may be impaired, leading to a reduced inhibition of cAMP-dependent protein kinase by insulin (36), and a sustained phosphorylation rate of inhibitor-1. Assuming that the concentration $(1.8 \mu \mathrm{M})$ and affinity $\left(\mathrm{ED}_{50}\right.$ = 3-4 nM) of inhibitor-1 are similar in humans to those observed in rabbit skeletal muscle (37), an effective concentra- 
tion of phosphorylated inhibitor-1 would be present under the conditions of the glycogen synthase phosphatase assay used here. This could account for the results generated by lowering glycogen synthase phosphatase activity.

In vivo, glycogen synthase may be a less suitable substrate for glycogen synthase phosphatase $(18,31,38)$; because we assayed human muscle glycogen synthase phosphatase using purified rabbit glycogen synthase $D$, the latter phenomenon is unlikely to explain our results.

That protein synthesis inhibitors prevent $(13,17)$ insulin from restoring normal levels of glycogen synthase phosphatase (13-17) in diabetic animals and that the $G$ component (39) of protein phosphatase- 1 is decreased in diabetic rat hepatocytes (16) strongly suggest that glycogen synthase phosphatase would be sensitive to the decreased rates of protein synthesis encountered in diabetic animal tissues (40).

As noted above, chronic insulin depletion reduces glycogen synthase phosphatase activity and insulin treatment regenerates this activity in animal tissues $(14,17)$. Results on acute insulin stimulation of phosphatase, however, have been varied $(9,14,17,30)$. Insulin stimulation of phosphatase activity was observed in rat skeletal muscle $10 \mathrm{~min}$ after insulin injection (9) and up to $30 \mathrm{~min}$ after insulin injection in rat heart muscle after starvation (30). Other studies in rat heart (17) and cultured hepatocytes (13) showed no insulin stimulation of phosphatase after acute hormone treatment. The results presented here show no insulin stimulation of phosphatase activity in human muscle. It is possible that no stimulation was observed because dilution during the assay procedure may have resulted in a dissociation of presumed insulin-induced noncovalently bound regulators of phosphatase activity. In addition, we are not aware of any report on stimulation of phosphatase activity beyond 10-30 min after insulin administration. Therefore, it is possible that an early activation of the phosphatase was missed by performing the muscle biopsies $30 \mathrm{~min}$ or more after beginning the insulin infusion. We thus cannot be certain that insulin does not activate glycogen synthase phosphatase in human muscle. In future investigations, we will address whether the phosphatase is stimulated by insulin in more concentrated homogenates, or in muscle biopsies obtained earlier after the beginning of insulin infusion.

In conclusion, in this study we have shown that insulin-resistant human subjects have decreased insulin-stimulated glycogen synthase activities, at least in part because of a reduced glycogen synthase phosphatase activity. Further investigation is needed to understand the mechanism of this decrease.

\section{Acknowledgments}

We thank the nursing staff, the dietary staff, and the technical staff for their professional assistance. We are also indebted to Susan Elson for her secretarial work. We are indebted to the Upjohn Pharmaceutical Company for their support, which made this study possible. Finally, we are grateful to the subjects for their cooperation during the studies.

\section{References}

1. Mandarino, L. J., K. S. Wright, L. S. Verity, J. Nichols, J. M. Bell, O. G. Kolterman, and H. Beck-Nielsen. 1987. Effects of insulin infusion on human skeletal muscle pyruvate dehydrogenase, phosphofructokinase, and glycogen synthase. J. Clin. Invest. 80:655-663.

2. Bogardus, C., S. Lillioja, K. Stone, and D. Mott. 1984. Correla- tion between muscle glycogen synthase activity and in vivo insulin action in man. J. Clin. Invest. 73:1185-1 190.

3. Lillioja, S., D. M. Mott, J. K. Zawadzki, A. A. Young, W. G. Abbott, and C. Bogardus. 1986. Glucose storage is a major determinant of in vivo "insulin resistance" in subjects with normal glucose tolerance. J. Clin. Endocrinol. \& Metab. 62:922-927.

4. Leloir, L. F., J. M. Olavarria, S. H. Goldenberg, and H. Carminatti. 1959. Biosynthesis of glycogen from uridine diphosphate glucose. Arch. Biochem. Biophys. 81:508-520.

5. Cohen, $P$. 1982. The role of protein phosphorylation in neural and hormonal control of cellular activity. Nature (Lond.). 236:613620.

6. Cohen, P. 1983. Protein phosphorylation and the control of glycogen metabolism in skeletal muscle. Philos. Trans. R. Soc. Lond. B. Biol. Sci. 302:13-25.

7. Ingebritsen, T. S., and P. Cohen. 1983. Protein phosphatases: properties and role in cellular regulation. Science (Wash. DC). 221:331-338.

8. Larner, J. 1983. Mediators of post-receptor action of insulin. Am. J. Med. 17:38-51.

9. Chang, L. Y., and L. C. Huang. 1980. Effects of insulin treatment on the activities of phosphoprotein phosphatase and its inhibitors. Endocrinologia. 95:427-432.

10. Nuttall, F. Q., M. C. Gannon, V. A. Corbett, and M. P. Wheeler. 1976. Insulin stimulation of heart glycogen synthase $D$ phosphatase (protein phosphatase). J. Biol. Chem. 251:6724-6729.

11. Oron, Y., G. Galasko, and J. Larner. 1980. Insulin action in intact mouse diaphragm II. Inhibition of endogenous protein phosphorylation. Mol. Cell. Biochem. 32:161-167.

12. Walkenbach, R. J., R. Hazen, and J. Larner. 1978. Reversible inhibition of cyclic AMP-dependent protein kinase by insulin. Mol. Cell. Biochem. 19:31-41.

13. Miller, T. B., Jr., A. K. Garnache, J. Cruz, and C. Wolleben. 1987. Regulation of glycogen metabolism in primary cultures of rat hepatocytes. J. Biol. Chem. 262:4000-4006.

14. Miller, T. B., Jr., A. K. Garnache, J. Cruz, R. K. McPherson, and C. Wolleben. 1986. Regulation of glycogen metabolism in primary cultures of rat hepatocytes. J. Biol. Chem. 261:785-790.

15. Margolis, R. N., H. P. Selawry, and R. T. Curnow. 1985. Regulation of hepatic glycogen metabolism: effects of diabetes, insulin infusion, and pancreatic islet transplantation. Metab. Clin. Exp. 34:62-68.

16. Bollen, M., and W. Stalmans. 1984. The hepatic defect in glycogen synthesis in chronic diabetes involves the $\mathrm{G}$ component of synthase phosphatase. Biochem. J. 217:427-434.

17. Miller, T. B., Jr. 1978. A dual role for insulin in the regulation of cardiac glycogen synthase. J. Biol. Chem. 253:5389-5394.

18. Khatra, B. S. 1984. Properties of phosphoprotein phosphatase from skeletal muscle and its regulation in diabetes. Proc. Soc. Exp. Biol. Med. 177:33-41.

19. National Diabetes Data Group. 1979. Classification and diagnosis of diabetes mellitus and other categories of glucose intolerance. Diabetes. 28:1039-1057.

20. Goldman, R. F., and E. R. Buskirk. 1961. A method for underwater weighing and the determination of body density. In Techniques for Measuring Body Composition. J. Brozek and A. Herschel, editors. National Academy of Sciences, National Research Council. Washington, DC. 78-89.

21. Rizza, R. H., L. J. Mandarino, and J. E. Gerich. 1981. Doseresponse characteristics for effects of insulin on production and utilization of glucose in man. Am. J. Physiol. 240:E630-E639.

22. Lusk, G. 1924. Animal calorimetry. Analyses of mixtures of carbohydrate and fat. J. Biol. Chem. 59:41-42.

23. Okubo, M., C. Bogardus, S. Lillioja, and D. M. Mott. 1988. Glucose-6-phosphate stimulation of human muscle glycogen synthase phosphatase. Metab. Clin. Exp. In press.

24. Steele, R. 1959. Influences of glucose loading and of injected insulin on hepatic glucose output. Ann. NY Acad. Sci. 82:420-430. 
25. Best, J. D., R. G. Judzewitsch, M. A. Pfeifer, J. C. Beard, J. B. Halter, and D. Porte, Jr. 1982. The effect of chronic sulfonylurea therapy in hepatic glucose production in non-insulin dependent diabetes. Diabetes. 31:333-338.

26. Kruszynska, Y. T., G. Petranyi, P. D. Home, R. Taylor, and K. G. M. M. Alberti. 1986. Muscle enzyme activity and insulin sensitivity in type I (insulin-dependent) diabetes mellitus. Diabetologia. 29:699-705.

27. Nahas, N., H. Juhl, and V. Esmann. 1984. Chromatographic characteristics and subcellular localization of synthase phosphatase, phosphorylase phosphatase and histone phosphatase in human polymorphonuclear leukocytes. Mol. Cell. Biochem. 58:147-156.

28. Goldstein, D. E., and R. T. Curnow. 1980. Impaired glycogen synthase activating system in human diabetic polymorphonuclear leukocytes. Diabetes. 29:217-220.

29. Komuniecki, P. R., R. G. Kochan, K. K. Schlender, and E. M. Reimann. 1982. Glycogen synthase in diabetic rat skeletal muscle: activation by insulin. Mol. Cell. Biochem. 48:129-134.

30. Gannon, M. C., and F. Q. Nuttall. 1984. Effect of prolonged starvation on glycogen synthase phosphatase activity in rat heart. $J$. Nutr. 114:2147-2154.

31. Gannon, M. C., A. W. H. Tan, and F. Q. Nuttall. 1981. Effect of starvation and insulin treatment on glycogen synthase $D$ and synthase D phosphatase activity in rat heart. Mol. Cell. Biochem. 34:3134.

32. Alemany, S., and P. Cohen. 1986. Phosphorylase a is an allosteric inhibitor of the glycogen and microsomal forms of rat hepatic protein phosphatase I. FEBS (Fed. Eur. Biochem. Soc.) Lett. 198:194-202.

33. Miller, T. B. Jr., A. Garnache, and J. J. Vicalvi, Jr. 1981. Hormonal regulation of hepatic glycogen synthase phosphatase. $J$. Biol. Chem. 256:2851-2855.

34. Gilboe, D. P., and F. Q. Nuttall. 1984. The synergistic action of caffeine or adenosine on glucose stimulation of liver glycogen synthase phosphatase activity. FEBS (Fed. Eur. Biochem. Soc.) Lett. 170:365369.

35. Gilboe, D. P., and F. Q. Nuttall. 1972. The role of ATP and glucose 6-phosphate in the regulation of glycogen synthase D phosphatase. Biochem. Biophys. Res. Commun. 48:898-906.

36. Gottschalk, W. K., and L. Jarett. 1985. Intracellular mediators of insulin action. Diabetes Metab. Rev. 1:229-259.

37. Foulkes, J. G., L. S. Jefferson, and P. Cohen. 1980. The hormonal control of glycogen metabolism: dephosphorylation of protein phosphatase inhibitor-1 in vivo in response to insulin. FEBS (Fed. Eur. Biochem. Soc.) Lett. 112:21-24.

38. Brown, J. H., R. D. Eichner, B. Thompson, and S. Mayer. 1980. Dephosphorylation and activation of exogenous glycogen synthase by adipose tissue phosphatase. Biochem. J. 188:221-228.

39. Straflors, P., A. Hiraga, and P. Cohen. 1985. The protein phosphatases involved in cellular regulation. Purification and characterization of the glycogen-bound form of protein phosphatase-1 from rabbit skeletal muscle. Eur. J. Biochem. 149:295-303.

40. Pain, V. M., E. C. Albertse, and P. J. Garlick. 1983. Protein metabolism in skeletal muscle, diaphragm, and heart of diabetic rats. Am. J. Physiol. 245:E604-E610. 